\title{
Types of Abortion Committed and Physical Complications as Correlate of Psychological Stress of Abortion among Female University Undergraduates in South- West Nigeria
}

\author{
Akinleye Grace Adetoun \\ Department of Guidance and Counselling, \\ Faculty of Education, \\ University of Ado-Ekiti, Nigeria.
}

\author{
Alade Folasade Adesola \\ Institute of Education, \\ Faculty of Education, \\ University of Ado-Ekiti, Nigeria
}

\begin{abstract}
The study examined the types of abortion committed and physical complications as correlate of psychological stress of abortion among female university undergraduates in South-West Nigeria. It specifically examined if types of abortion committed by female university undergraduates and physical complications experienced could lead to psychological stress. The research design used in this study was an exploratory type. The population was all the female university undergraduates in the various federal and state universities in the six states of South West Nigeria. The sample consisted of 1,200 single and married female university undergraduates selected from six universities using stratified random sampling, simple random and purposive sampling techniques. The research instrument titled "Psychological Stress of Abortion Questionnaire (PSYCHOSA)" was used to collect data from the respondents. The test re-test reliability of the instrument was ensured and a reliability co-efficient of 0.74 was obtained at 0.05 level of significance. The face, content and construct types of validity of the instrument were ascertained by experts in Tests and Measurement, Psychology and Guidance and Counselling. Two hypotheses were formulated to guide the study. The data collected were analysed using t-test statistics. The result of the analysis showed that types of abortion committed and physical complications of abortion among female university undergraduates had no significant influence on psychological stress of abortion among these students. Based on the findings, it was recommended that government should make provisions for counsellors in all the universities. Counsellors in various institutions should devise means of interacting with female University undergraduates to know what they are passing through and be ready to show emphatic understanding anytime. Also, since abortion is allowed to save a woman's life, student doctors and all medical practitioners should be trained to carry out abortion with a very low risk of complications.
\end{abstract}

\section{Introduction}

Abortion has become rampant all over the world. It is a common issue among the teenagers and adult women in the society. Issues relating to abortion has been on and generated a heated argument and distressing statistics concerning abortion have been documented.

Abortion has been defined in a number of ways. According to Ihediwa-Okoro [6], abortion may be spontaneous in which case, the foetus was expelled due to accidental trauma, natural cause or environmental. It may equally be induced by deliberate human effort. According to him, this is a calculated forced ejection of foetus from the uterus. Abortion is defined by Bakare [1] as the termination of pregnancy before foetal viability. Roche [11] believed the term 'abortion' is synonymous with induced abortion while in medical texts, the word 'abortion' might exclusively refer to spontaneous abortion which could also be referred to as miscarriage.

National Training Manual [8] defines abortion as the ending of a pregnancy before the baby in the womb is able to stay alive outside the mother's body. In another re-printed version of the manual, abortion is the termination of a pregnancy on or before twenty-four weeks of pregnancy. According to the manual, it is estimated that about $40 \%$ of maternal deaths are from abortion and its complications. There are about 610,000 unsafe abortions in Nigeria annually. In a study of 1000 female adolescents in Benin City, it was found that $68.8 \%$ of unintended pregnancies ended in induced abortion. In another study, in Ilorin, $74 \%$ of the 264 women who presented with complications from induced abortion were adolescents. Also, Odeh [9] gave an alarming rate of 760,000 abortions yearly resulting in 140,000 hospitalisations in Nigeria.

Strong, Devault, Sayad and Yarber [14] also believed when most people hear the word 'abortion', they think of a medical procedure. But abortion, or expulsion of the concept us, can happen naturally or can be made to happen in one of the several ways. Many abortions occur spontaneously because a woman suffers a physical trauma because the concepts is not properly 
developed, or more commonly, because physical conditions within the uterus break down and end the development of the concepts. Researcher like Roche[11], strong, Devault, sayard and yarber [14] and world Health organisation [15] categorised abortion into several ways which include: Surgical abortion:- This include:

- Spontaneous abortion / miscarriage: This is commonly referred to as miscarriage. It occurs when pregnancy ends before the baby has any chance of survival. Most spontaneous abortion occurs in the first 12 weeks of pregnancy. It may occur if a woman has a serious febrile illness such as malaria, has a severe fall, or if the pregnancy is ectopic.

- Complete abortion: Abortion is described as complete when all the tissues of the developing embryo or foetus and the placenta have passed out through the vagina, when abortion is complete, the bleeding will stop after a few days.

- Incomplete abortion: Abortion is incomplete when part of the products of pregnancy remains inside the uterus.

Induced abortion: This is the deliberate termination of pregnancy for various reasons such as threat to the life of the pregnant woman or for social reason.

\section{Surgical Abortion: This includes:}

(i) Vacuum Aspiration- It is performed under local anesthesia. The first step involves the rinsing of the vagina with an antiseptic solution. Next, the cervix is dilated with a series of graduated rods. Then a small tube attached to a vacuum is inserted through the cervix. The uterus is gently vacuumed, removing conceptus, placenta and endometrial tissue. If the pregnancy is less than 9weeks, a large syringe may be used. The entire process takes 10-15 minutes.

(ii) Dilation and Curettage (D \& C)- This is a standard gynaecological procedure performed for a variety of reasons. This is cramping with curette, a small, spoonshaped instrument. According to Healthwise [5], the patient returns home the same day, she will experience cramping, bleeding and possibly emotional reactions over the following days. This is a first trimester procedure.

(iii) Dilation and Evacuation (D \& E)- This is usually performed during the second trimester of pregnancy, but it can be done up to week 20 or beyond. Local or generated anesthesia is used. The cervix is slowly dialated and the foetus is removed by alternating curettage and other procedures. It is a second trimester procedure, therefore it is somewhat riskier and often more traumatic than a firsttrimester abortion.

Legal abortions: This can be performed if the life of the woman will be jeopardized by the pregnancy.

Unsafe abortions: This usually occurs where abortion is illegal. In some cases, women or adolescents may try to end their pregnancies by themselves or with the assistance of untrained personnel. The World Health Organization [15] defines unsafe abortion as a procedure carried out by persons lacking the necessary skills or in an environment that does not conform to minimal standards or both. All those who do not have medical training and even professionals operating under sub-standard conditions are included.

Crude form of Abortion: The crude form of Abortion is unsafe method of abortion according to Simon [12]. It involves the use of herbs reputed to pose as abortifacient properties or insertion of nonsurgical objects such as knitting needles and clothes hangers into the uterus. The use of sharpened implements and the application of abdominal pressure were also said to be adopted in crude form of abortion.

Therapeutic Abortion: Therapeutic abortion according to Roche [11] is an abortion performed to save the life of the pregnant woman to preserve the women's physical or mental health and to terminate pregnancy that would result in a child born with a congenital disorder that would be fatal or associated with significant morbidity.

Researchers have also noted that some abortions are done traditionally. Some of the traditional methods used according to Ciganda and Laborde [2] include inserting harmful objects into the vagina, swallowing special concoctions, taking very high doses of quinine, forcefully massaging the abdomen and washing out the vagina with harsh chemicals such as bleach. These can have grave consequences on women, their families and the society as a whole. The procedures can endanger women's reproductive health and could lead to serious as well as life threatening complications which include perforation of the uterus, fainting and death. National training manual [8], while commenting on complications of abortion had it that it is a common phenomenon among adolescents and young adults all over the world. The complication, especially when it is unsafe is multiple because the client can have an incomplete abortion, which could result in infection, bleeding and physical trauma. 
Researchers have equally shown that women suffer psychological effects following abortions. Fogel [4] affirmed that a psychological price is paid after abortion. According to him, one cannot deny that something is being created and that this creation is physically happening. Dene [3] is compelled to admit that abortion, though justifiable, is a 'type of murder' because its victim is 'alive and human'. Other findings supporting these are that of Sobie and David [13]. The former have found out that reports of more severe pain during abortion among younger women are linked to greater levels of anxiety and fear prior to the abortion while the later found out that the teens consider the abortion procedure itself to be stressful and associated with feelings of guilt, depression and a sense of isolation. Mitsunga, Mitsunagga, Larsen and Okonofus [7] also believed that unsafe abortions can have dire consequences for women, their families and society as a whole for women, their families and society as a whole. Such procedures according to them can endanger women's reproductive health and lead to serious often lifethreatening complications. This study therefore is focussed on types of abortion committed and physical complications as correlate of psychological stress of abortion among female University undergraduates in south-west Nigeria.

\section{Research Rationale}

Reports and observation from all over the world have shown that abortion is prevalent among women, especially among young girls. This could be as a result of pre-marital sex among youth which is now prevalent among girls. Observations from the higher institutions nowadays reveal that undergraduate students indulge in illicit sex affairs. The WHO [12] observed that most of these girls indulge in these illicit sexual activities to make ends meet. This could be as a result of economic condition in the country coupled with increase in school fees in all the universities and the diminishing ability of families to support their children's' education. The implications therefore, are high rate of unwanted pregnancies among Nigerian youths and its continuation may take a heavy toll on a woman's physical and emotional well-being which has led most women, especially the under-graduates into committing various types of abortions. This could lead to psychological stress. It is against this background that the researcher tried to find out if types of abortion committed and physical complication could lead to psychological stress after abortion among female university undergraduates in South-West, Nigeria. To find solution to this problem, one general question was raised and two research hypotheses were formulated to guide the study.

\subsection{General Question}

What are the various types of abortion committed by the female university undergraduates in SouthWest Nigeria?

\subsection{Research Hypotheses}

1. Types of abortion committed have no significant influence on psychological stress of abortion

2. Physical complications of abortion among female university undergraduates have no significant influence on psychological stress of abortion.

\section{Methodology}

The research design used in this study was an exploratory type. It involves the distribution of large copies of the instrument to the respondents in order to sieve the desired sample from the respondents.

The target population for the study comprised all female undergraduates (single and married) in the various Federal and state universities in the six states in South West Nigeria. These six states are: Lagos, Oyo, Ogun, Osun, Ekiti and Ondo. There were five federal and seven state universities in these states at the period of the study.

The sample consisted of 1,200 female university undergraduates selected from six universities based on multistage sampling techniques. The first stage was purposive selection of all the states. The second stage was the stratification of universities into federal and state, the third stage was random selection of three universities each from both federal and state universities, making six universities while the fourth stage was purposive selection of female undergraduates who had procured abortion. These comprised of both single and married female university undergraduates who were freshers and returning students and had committed abortion.

The instrument used in this study was an adapted questionnaire titled "Psychological Stress of Abortion Questionnaire (PSYCHOSA)”. Some of the items were adapted from the psychological reactions reported after abortion by Reardon [7].

The instrument consisted of two sections, Sections A and B. Section A contained contextual variables such as background characteristics of the respondents such as age, religion, academic and marital status of the students, types of abortion committed, and ethnic background while section B contained 40 items out of which 23 items were adapted from the instrument of Reardon [7]. A four point scale measuring tool was used to analyse the data. 
Experts in the field of the study ensured its face and content validities. They reviewed the items in terms of simplicity and clarity to remove ambiguity among respondents. The experts agreed that the instrument was capable of eliciting responses from the respondents on psychological stress of abortion.

The reliability of the instrument was ensured using split half method. This is a measure of internal consistency. A single test was administered on thirty respondents at a single sitting. Two scores were obtained from each test, one set from the odd and another from the even numbered items. Pearson product moment correlation was used to get the correlation between the two sets of scores which provided a measure of reliability for each half of the test. Spearman - Brown formula was then used to get the reliability of the full length of the test. The internal consistency of 0.86 was obtained at 0.05level of significance which was found to be reasonable and reliable for the study. The instrument was administered by the researchers and some trained research assistants who were quite familiar with the various universities used.

In few of the universities, copies of the questionnaire were collected back on the spot, while appointed dates were given for the collection of the remaining copies of the questionnaire.

The data collected were analysed using t-test statistical tool. The hypothesis was tested at 0.05level of significance.

\section{Result}

\section{Descriptive Analysis}

General Question- What are the various types of abortion committed by the female university undergraduates in South-West Nigeria?

\section{Table 1. Frequency counts and Percentages Showing Types of Abortion Committed by Female University Undergraduates}

\begin{tabular}{|l|l|l|}
\hline Variables & Frequency & Percentage \\
\hline Miscarriage(Spontaneous) & 162 & 14.6 \\
\hline $\begin{array}{l}\text { Intentional Abortion/ } \\
\text { induced }\end{array}$ & 944 & 85.4 \\
\hline Total & 1106 & 100.0 \\
\hline
\end{tabular}

Table 1 reveals that 944 (85.4\%) of the female university undergraduates had intentional abortion while only $162(14.6 \%)$ of the abortion cases were as a result of miscarriages. This implies that intentional abortion is more prominent among female university undergraduates.
This section presents the testing of the two hypotheses formulated for this study. T-test analysis was used to test the two hypotheses generated and tested at 0.05 level of significance.

\section{Hypothesis 1}

Types of abortion committed have no significance influence on psychological stress of abortion among female university undergraduates.

Data were analysed using t-test; as presented in table 2

Table 2. t-test analysis on Types of Abortion committed and Psychological Stress after Abortion

\begin{tabular}{|l|l|l|l|l|l|l|}
\hline Group & $\mathrm{N}$ & $\mathrm{X}$ & $\mathrm{SD}$ & $\mathrm{df}$ & $\mathrm{t}$-cal & $\begin{array}{l}\mathrm{t}- \\
\text { table }\end{array}$ \\
\hline Miscarriage & 162 & 120.27 & 28.61 & & & \\
\hline $\begin{array}{l}\text { Intentional } \\
\text { abortion }\end{array}$ & 944 & 122.02 & 28.93 & 1085 & 0.71 & 1.96 \\
\hline
\end{tabular}

$\mathrm{P}>0.05$

Table 4 shows that the t-table was 0.71 while its corresponding table value at (0.05) level of significance was 1.96. The null hypothesis is thereby accepted. Since t-cal is less than t-table, therefore, types of abortion committed by female university undergraduates had no significant influence on psychological stress after abortion. This implies that types of abortion committed had no significant influence on psychological stress of abortion among female university undergraduates.

\section{Hypotheses 2}

Physical complications of abortion among female University undergraduates have no significant influence on psychological stress of abortion.

Table 3. t-test of Physical Complication and Psychological Stress after Abortion

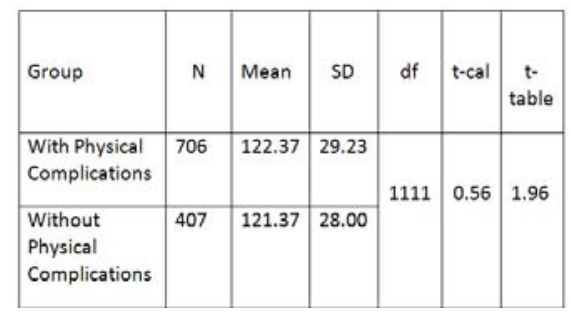

$\mathrm{P}>0.05$

\section{Hypotheses Testing}


Table 3 shows that t-cal (0.56) is less than t-table (1.96) at 0.05level of significance. The null hypothesis is accepted. Therefore, physical complications of abortion among female university undergraduates had not significantly influenced psychological stress after abortion. This implies that physical complications after abortion did not influence psychological stress among female undergraduates.

\section{Discussion}

The study examined types of abortion committed and physical complications as a correlate of psychological stress of abortion among female university undergraduates in South-West Nigeria. It further revealed that various types of abortion committed by the female university undergraduates had no significant influence on psychological stress after abortion. This showed that all the types of abortion elicited psychological stress but sometimes, it turned out that those who had intentional abortion experienced more psychological stress after abortion. This could be due to the fact that majority of them are in schools and not yet ready for parenthood. The findings agreed with that of the World Health Organisation [12] which reported that abortionists are undergraduates and this is as a result of societal pressures. The findings also revealed that physical complications of abortion among female university undergraduates had no significant influence on psychological stress after abortion. One will expect the physical complications to influence psychological stress after abortion but it could be argued that since the whole process, both induced and spontaneous are stressful, physical complications alone will not influence psychological stress after abortion among female university undergraduates. This was supported with the submission of Sobie and David [13]. The former have found out the reports of more severe pain during abortion while the later found out that the teens consider the abortion procedure itself to be stressful and associated with feelings of guilt, depression and a sense of isolation. Conversely, Mitsunga, Larsen and Okonofus [5] believed it is unsafe abortions that can have dire consequences for women, their families and society as a whole. According to them, such procedures can endanger women's reproductive health and lead to serious life threatening complications.

\section{Recommendations}

Based on the findings of the study, the following recommendations were made:

1. Government should make provisions for counsellors in all the universities to provide counselling services towards abortion for young people so that the number of abortions and physical complications could reduce significantly among female university undergraduates.

2. Counsellors in various institutions should devise means of interacting with female University undergraduates to know what they are passing through and be ready to show emphatic understanding anytime. This could encourage them to share anything they are passing through with the counsellor for necessary intervention.

3. Health professionals should provide contraceptive information and services to female undergraduates and enlighten them on the consequences of abortion.

\section{References}

[1] Bakare, N.A. (2006). Teenage pregnancy, causes, medical implications and prevention. Network Printers.

[2] Ciganda, C \& Laborde A (2003). Herbal infusions used for induced abortions. Journal of Toxicol clin Toxicol, 41 (3), 255-9. Retrieved 2008-01-26.

[3] Dene, M. (1989): “The real anguish of abortions” The Washington Post.

[4] Fogel, J. (1989): “The real anguish of abortions”. The Washington Post.

[5] Healthwise (2004): Manual and Vacuum aspiration for abortion. Web MD. Retrieved 2006-08-19.

[6] Ihediwa-Okoro, B.N (2008): Post-abortion psychological sequelae: Counselling for healthy living. A paper presented at the $32^{\text {nd }}$ Annual National Conference of Counselling Association of Nigeria, Ilorin.

[7] Mitsunaga T.M, Larsen U.M \& Okonofua, F.T (2005) Risk factors for complications of induced abortions in Nigeria, Journal of Women's Health. 14(6), 515-528

[8] National Training Manual (2005). Family planning. Training for physicians and Nurses/Midwives. Abuja: Vision project. P.

[9] Odeh, O(2007 May,22). Daily Independent, p E6.

[10] Reardon, D. (1994). "Psychological reactions reported after abortion”. The Post - Abortion Review Fall 2(3); 4-8.

[11] Roche,N.E (2004) Therapeutic abortion. (Access date: 03/08/2006).

[12] Simon, S. (2002 March, 24) "Abortion foes seize on reports of cancer link in Ad - campaign” Los Angeles Times. Retrieved 2006-01-11 
[13] Sobie, A.r \&David, R.C (2001). Detrimental effects of adolescent abortion. Elliot Institute.

[14] Strong, B., Devault, C. S., Sayad, B.W. \& Yarber, W.L. (2005). Human sexuality. Versailles: Quberbecor World.

[15] World Health Organisation (2004). Unsafe abortion global and regional estimates of unsafe and associated mortality in 2000. Geneva: WHO Publication. 